\title{
Article
}

\section{Factors affecting the identification of talented junior-elite footballers: a case study}

Reeves, Matthew, Roberts, Simon J, McRobert, Allistair P and Littlewood, Martin

Available at http://clok.uclan.ac.uk/25213/

Reeves, Matthew ORCID: 0000-0002-3903-2910, Roberts, Simon J, McRobert, Allistair P and Littlewood, Martin (2018) Factors affecting the identification of talented junior-elite footballers: a case study. Soccer \& Society, 19 (8). pp.

1106-1121. ISSN 1466-0970

It is advisable to refer to the publisher's version if you intend to cite from the work. http://dx.doi.org/10.1080/14660970.2018.1432383

For more information about UCLan's research in this area go to http://www.uclan.ac.uk/researchgroups/ and search for <name of research Group>.

For information about Research generally at UCLan please go to http://www.uclan.ac.uk/research/

All outputs in CLoK are protected by Intellectual Property Rights law, including Copyright law. Copyright, IPR and Moral Rights for the works on this site are retained by the individual authors and/or other copyright owners. Terms and conditions for use of this material are defined in the policies page.

\section{CLoK}

Central Lancashire online Knowledge www.clok.uclan.ac.uk

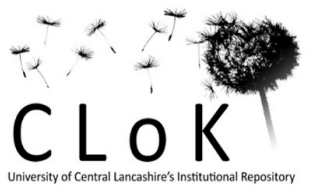




\section{Factors Affecting the Identification of Talented Junior-Elite}

\section{Footballers: A Case Study}

Matthew J. Reeves,,${ }^{1,2}$ Simon J. Roberts, ${ }^{1}$ Allistair McRobert, ${ }^{3}$ Martin

Littlewood $^{3}$

${ }^{1}$ Sport Coaching Research Group, Liverpool John Moores University, IM Marsh

Campus, Barkhill Road, Liverpool, L17 6BD.

${ }^{2}$ Research In Sport, Liverpool, UK.

${ }^{3}$ The Football Exchange, Liverpool John Moores University, 70 Great Crosshall Street, Liverpool, L3 $2 A B$.

Matthew J. Reeves

Email: m.j.reeves@ljmu.ac.uk

Tel: +44(0)1512315325 


\section{Factors Affecting the Identification of Talented Junior-Elite Footballers: A case study}

The purpose of this study was to identify and examine factors associated with the identification of talented junior-elite footballers. Three data collection methods were employed: (1) document analysis (4 documents, 222 pages), (2) overt observation ( 105 hours), and (3) 12 semi-structured one-to-one interviews with staff responsible for player recruitment ( $\mathrm{M}=70$ minutes). Data were analysed using a constant comparative approach, meaning newly collected data were compared with previously collected data, allowing flexibility and reflexivity throughout the data collection period. Two core themes associated with the identification of talented junior-elite footballers at this academy emerged: "structural issues", and "current performance and potential talent". "Structural issues" were further categorised as: (1) financial; (2) educational; (3) philosophical or cultural; (4) competition amongst clubs; and (5) hours in practice. "Current performance and potential talent" covered issues around growth, maturation and development and psycho-social attributes of players. The paper concludes by suggesting that clubs should be more proactive in understanding the structural issues that affect their talent identification processes, and better educating and supporting staff in their understanding of growth, maturation, and development.

Keywords: talent, elite, structural issues, recruitment, potential, case-study 


\section{Introduction}

It is widely reported that talent identification (TI) is a non-linear, dynamic, and complex process. ${ }^{1}$ However, despite TI being at the forefront of many sport systems no accepted definition of TI exists. ${ }^{2}$ As this focus for this study will be TI in football we have adopted the Williams and Reilly ${ }^{3}$ definition of talent identification: "Talent identification refers to the process of recognizing current participants with the potential to become elite players." However, it is widely accepted that there is no universal or agreed definition for TI and there have also been criticisms of the interchangeable choice of terms and language associated with the grouping of athletes within both the TI and talent development (TD) process. ${ }^{4}$ To reconcile this issue, the term junior-elite (i.e. academy-level players) is adopted throughout the remainder of this paper following previous calls in the literature. ${ }^{5}$

The complexity of the TI process is exacerbated by conflicting arguments surrounding the evidence for what attributes (i.e. physical, physiological, psychological, sociological, technical, tactical) act as the most stable predictor of future success. For some, it is the role of sport-specific, long-term development programmes, to provide the stimulus for the early recruitment of athletes. ${ }^{6}$ The assumptions underlying early specialisation is that it takes a significant amount of time, effort, and energy to achieve elite performance in a specific domain. There is, however, evidence that suggests children might be better left to mature and develop across multiple sport domains. ${ }^{7}$ Furthermore, studies have demonstrated that elite performers participated in a number of sports and activities during childhood, ${ }^{8}$ and early specialisation can actually be negatively correlated with eventual success and elite performance. ${ }^{9}$ Despite this supposition, there is evidence that some sports require specialisation within a particular age range. For example, in their systematic review of talent determinants in racquet 
sports, Faber and colleagues ${ }^{10}$ suggest that international peak performance is achieved between 14-18 years of age, a period referred to as the specialising phase ${ }^{11}$ of sport involvement.

Whilst attempts have been made, using various methodological approaches, to determine the most effective TI system for football ${ }^{12}$ there remain doubts over the scientific foundations of many TI systems. ${ }^{13}$ Criticisms of TI strategies include their low predictive value and validity and their inability to retain participants within sport once de-selected. ${ }^{14}$ Despite such criticisms, national governing bodies of sport, professional clubs, and other associated organisations continue to invest substantial resources into identifying potentially talented individuals. ${ }^{15}$

The inception of academies, initiated by the Football Association (FA) ${ }^{16}$ and recently re-developed through the Elite Player Performance Plan (EPPP) ${ }^{17}$ has brought about significant changes to junior-elite football. For example, academies are now regularly audited on their 'performance' by the Premier League in order to determine their category status. An academy's category status ranges from category one to category four, and is dependent on a range of measureable factors, including player productivity statistics (i.e. how many players they develop through their academy to professional status), to the facilities and resources available. ${ }^{18}$ Furthermore, the EPPP states that the recruitment of players can begin from nine years of age, when a player becomes eligible to become registered with a professional club. ${ }^{19}$ However, many clubs operate pre-academies, where players are unable to register with a club, but are able to be trained and developed by clubs.

Attempts to identify the factors associated with talent have tended to focus on, and prioritise, physiological, anthropometrical, and physical measures. ${ }^{20}$ However, within the football-specific literature, there has been a recent shift toward examining the 
psycho-social attributes associated with TD within junior-elite football. ${ }^{21}$ Since TI is concerned with recognising future potential, with no agreed definition, studies tend not to discuss the subtleties included in identifying talent; instead they propose a predetermined format for talent (usually physiologically or psychologically derived) before advancing some form of objective measurement. ${ }^{22}$ Indeed, most quantitative assessments of talent tend to focus on discrete, epigenetic attributes, such as speed, strength, agility, or endurance. ${ }^{23}$ Recently, there have been validation studies of skillbased assessment tools for TI which, ${ }^{24}$ alongside the Loughborough Soccer Passing Test, ${ }^{25}$ are the only football-based assessments of potential talent of which we are aware. It is important to highlight that such skill-based tests are not tests of talent and are, therefore, unlikely to make any meaningful suggestion of future potential. So, whilst many TI and TD studies, have tended to adhere to post-positivist methods of inquiry (i.e. adopting multiple measures or observations to better understand reality) ${ }^{26}$ and have added to our knowledge and understanding of TI and TD, it also leaves us in a narrow philosophical position. Indeed, there are a dearth of qualitative studies designed to understand the 'whys' of TI and TD. Too often academic inquiry investigates phenomena, but fails to consider the applied implications from a practitioner perspective. In this study, we attempt to bridge this gap by allowing the voice of those involved in the TI process to share their experiences specifically within junior-elite football.

The seminal work of Williams and Reilly ${ }^{27}$ proposed a model of potential predictors of talent in football. Their model included physical, physiological, psychological, and sociological domains with accompanying sub-components. However, the model has frequently been used to underpin studies that have examined the physical and physiological domains,${ }^{28}$ though less often the psychological and social 
ones. So, whilst the process of TI is considered ineffective, due to the number of variables and intangibles the broader concept of TI in football also remains problematic. As Miller and colleagues suggest, "TI is, then, and at its core, a process of judgement, operationalised against a backdrop of timing, resources and opportunity". ${ }^{29}$ Whilst TI may well be affected by timing, resources, and opportunity, we currently do not know, or understand whether these are correctly asserted, or whether they are broad overviews of what may be a much larger, more complex and dynamic system in junior-elite football.

As alluded earlier, there are a limited number of qualitative, football-specific, TI studies. Where those studies exist, they have tended to sample players, ${ }^{30}$ coaches,${ }^{31}$ parents, ${ }^{32}$ or a combination of these groups. ${ }^{33}$ However, recruitment staff have failed to be included in previous studies. The purpose of this study therefore, is to qualitatively explore the factors that affect the identification of junior-elite footballers from the perspective of key stakeholders, including recruitment staff, at a UK category one football academy.

\section{Methodology}

A qualitative approach, adopting an exploratory case study design was utilised. A case study design allowed the researcher the flexibility to obtain meaningful and contextual data that would best explore factors associated with identifying talented young footballers in a category one football academy. As Crabtree and Millar ${ }^{34}$ remind us, the one advantage of a true case study design is that it allows collaboration between the researcher and the participants, and enables the participants to tell their stories. As such, these narrative accounts allow the participants to describe their views of reality enabling the researcher to better understand the participants' actions and motives. ${ }^{35}$ 


\section{Participants and Setting}

Using purposive sampling procedures, the participants were all full-time, professional staff who worked in a category one football academy located in the North of England. The academy was attached to a Premier League club and was selected because of its success and productivity in creating professional footballers; not just in the Premier League, but in all tiers of football. The academy has 32 full time members of staff, an additional 20 part-time members of staff, and operates 12 age groups (under six to under 21). Part-time members of staff did not include zero-hours contracted and ad-hoc staff, such as scouts.

The participants were selected based on their role in either the identification (i.e. recruitment staff) or development (i.e. coaches) of junior-elite footballers. The participants $(n=12)$ were initially contacted by email to gauge their interest and willingness to participate in the study. There was a $100 \%$ positive response rate to being involved with the study. A series of follow up phone/face-to-face conversations were then conducted to fully outline the purpose of the study. The participants included three recruitment staff, four coaches, and five members of the academy management team (AMT). All participants have been assigned pseudonyms (see Table 1). Members of the AMT included the academy director; head of recruitment; head of sport science; head of education and welfare; and senior coach educator. All the participants were male with varied experiences of working within academy football. For instance, Paul (recruitment department) had only recently joined the club's recruitment department having previously worked in an unrelated sector, whereas Josh (head of recruitment; AMT) had over 20 years' experience working in recruitment for junior footballers. Participants' professional involvement in junior-elite football ranged from less than one year to 24 years, though involvement in football (i.e. playing, coaching, recruitment), overall, ranged from 20-50 years. 
Ethical approval was provided by a central university ethics committee and written informed consent was obtained from all participants before data collection began. In all instances pseudonyms, have been applied to any direct quotations where individuals' names were used.

Table 1: Staff characteristics and Pseudonyms

\begin{tabular}{ccc} 
Role / Department & Pseudonym & $\begin{array}{c}\text { Years involved in } \\
\text { youth football }\end{array}$ \\
\hline Full-time recruitment staff / & Paul & 0 \\
Recruitment department & Kevin & 5 \\
Jon & Jim & 12 \\
Full-time coach / & Jake & 13 \\
Coaching department & Peter & 9 \\
\hline Academy director / AMT & Jerome & 6 \\
\hline Head of recruitment / Recruitment & Scott & 18 \\
department / AMT & Josh & 24 \\
Head of Sports Science / Sports science & & 14 \\
department / AMT & Liam & 20 \\
Head of coach education / Coaching \\
department / AMT & Andy & 15 \\
Head of Education \& Welfare / Education \& & Mike & \\
Welfare department / AMT & & \\
\hline
\end{tabular}

\section{Data Collection}

Data collection occurred over a 12-month period, and utilised three data collection protocols: document review, face-to-face interviews, and overt observational fieldwork were used. This operationalising of multiple data collection methods allowed for triangulation of data, meaning enhanced trustworthiness of the research findings. ${ }^{36}$

\section{Document Review}

Modern organisations, including football clubs, are dependent upon paperwork. ${ }^{37}$ Indeed, in the EPPP era, football clubs are required to make certain documentation readily available for audit purposes. This provided a window through which examination of the clubs TI processes and philosophy could be considered. ${ }^{38}$ 
Artefacts reviewed included information provided directly to the researcher, such as the coaching operations manual (electronic document 76 pages), and academy performance plan (electronic document, 46 pages); and indirectly, such as freely available information on the club's website (i.e. annual reports). When reviewing the artefacts, information relating to the identification and development of players was identified.

\section{Interviews}

All interviews were semi-structured in nature with an associated interview schedule to ensure specific TI topics were covered, ${ }^{39}$ but leaving suitable flexibility to examine any particular issues further. All interviews were conducted in a private room located in the academy building. The interview schedule consisted of three broad themed areas: knowledge and understanding of TI; club specific processes, policies, and strategies; and external factors. The first section included questions concerned with eliciting responses about participants' understanding about what talent is, what it means to them, and how they have informed these conceptions. Secondly, questions focussed on the club's specific TI policies, strategies, processes, and philosophy. Participants then explored factors concerned with anything outside of the club that might impact upon TI, such as the EPPP. ${ }^{40}$ Finally, participants were offered an opportunity to discuss any issues they felt maybe pertinent to the study and to ask any questions they might have had. Interviews ranged in length from 52 minutes to 97 minutes ( $M=70$ minutes). All interviews were digitally recorded and transcribed verbatim.

\section{Observational Fieldwork}

The first author was afforded access to the academy in order to observe and interact with members of academy staff (105 hours in total). This included formal activities, for example: observing practical coaching sessions, sitting in meetings where 
player TI was discussed, to more informal activities such as 'ad-hoc' conversations over coffee. Due to the spontaneous nature of these informal activities, no audio recording device was activated during these interactions. Following each observation and informal interaction detailed field notes were compiled and interactions that focussed on any issues related to TI were recorded. Field notes were compiled either longhand or via the use of an electronic notebook and were written up in private before leaving the academy environment. All field notes were eventually digitised and represented 25 single-spaced A4 pages. Covert field work was not a viable option as the first author was not able to be present at the academy as a full-time member of staff. Furthermore, the purpose of the first author's presence was known as interviews were conducted early in the data collection process, making overt observational fieldwork a more appropriate data collection method.

\section{Data Analysis}

All interviews were digitally recorded and transcribed verbatim; club documentation was provided in digital format; and all field notes were, if not already, digitised. Once all data sets were in a digital format they were imported into QSR NVivo 10 and subjected to a constant comparative method of analysing data. ${ }^{41}$ Data analysis began concurrently with data collection, with documentation first subjected to the process of open and axial coding to determine concepts and categorisations. Interview data were than coded into the existing concepts and categories created through examining club documentation. The final data set, observational data, were also coded into the concepts and categories identified during the first two data analysis processes. 


\section{Open Coding}

The process of open-coding is to identify concepts and their associated properties and dimensions. ${ }^{42}$ Consequently, data were initially broken-down and examined during the open-coding process; similarities and differences were identified to develop concepts. For example, raw data extracts related to 'structural issues' were identified from the club documentation, and then attempts were made to delineate between the myriad of internal and external structural issues. As the open-coding procedure continued, and a process of comparative analysis took place; concepts with similar characteristics were grouped together or, where there were no similarities between data units and existing concepts, new concepts were generated. Concepts that embraced similar articulations were collated as categories (i.e. higher order level) and sub-categories. Descriptive labels, which defined the essential characteristics of each category or sub-category were applied to assist the characterisation process. ${ }^{43}$

\section{Axial Coding}

Axial coding was undertaken to reassemble to data that had been broken down during the open-coding process. ${ }^{44}$ Through axial coding the categories, sub-categories, and concepts were developed to produce more accurate descriptions of the factors associated with identifying talented junior-elite footballers. Data were conceptually developed by asking questions related to philosophies, processes, and practice. Once axial coding was completed with the club documentation data set, and a schema of concepts, sub-categories, and categories created, the interview data were introduced into the data analysis. It was important that the interview data were not forced into the existing conceptual framework, but that constant comparison continued to examine the similarities and differences between data sets. ${ }^{45}$ Therefore, interview data that aligned to existing concepts were included in those concepts to add further depth and richness. 
However, if any of the interview data did not align with existing concepts a new concept was created. The same process was undertaken for the observational data set. As the observation data were coded the three data sets were combined to create the most comprehensive, rich, and detailed themes.

Categories Core Themes

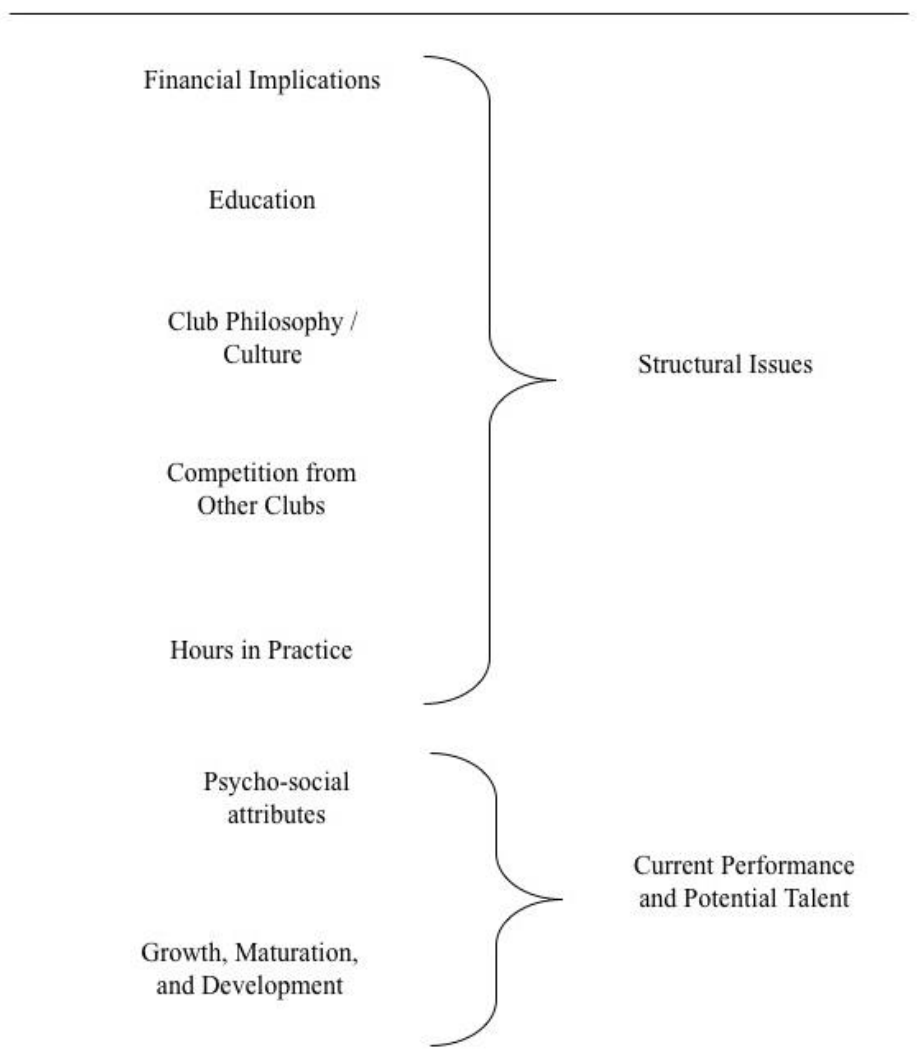

Figure 1: Overview of the core themes and categories pertaining to factors affecting the identification of talented junior-elite footballers.

\section{Findings \& discussion}

Findings were derived through a process of inductive analysis and verification that resulted in two core themes associated with the factors affecting the identification of talented junior footballers: (1) Structural issues, and (2) Current performance and 
potential talent. These core themes, and associated categories are presented in Figure 1. Narratives are sometimes used that replicate the types of conversations and interactions that occurred for the purpose of presenting the observational data set.

\section{Structural Issues}

There are a number of structural considerations for football academies in the UK to consider, not least the EPPP. Still in its first iteration, the EPPP makes particular demands of each club, dependent on which category status a club has achieved during audit. However, the requirements of the EPPP are only part of the structural jigsaw that the category one academy involved in this study highlighted. For example, internal structural issues, such as finance, were also apparent and will be discussed in more detail below. Club documentation data clearly laid out the club's position on a number of factors, including the overall club philosophy and playing philosophy. Interview data highlighted issues in the (non)interaction of structural issues such as playing philosophy and 'on-the-ground' TI practice.

\section{Financial Implications}

The most extensive structural issue focussed on financial implications associated with identifying talented youngsters. Implications were not just focussed on the club, but highlighted the significant personal and financial implications for players and parents. The financial commitment required from players and parents in order to attend training, games, and other associated events, such as national and international tours. ${ }^{46}$ It was suggested that football had now become less of a working-class sport, and that newly recruited players were from more affluent backgrounds with parents able to financially support their involvement. 
"I think the game has become more of a middle-class game, as the people who can afford it are getting their boys to coaching, and they're getting identified." (Kevin, recruitment department)

"It's a lot, really. I don't think I'd be able to afford most of what some of these parents do...there's a lot of 'em who don't miss a tour or anything. You know, they're at training three or more times a week, games at weekend and then tours when they're on. It must cost a fortune, I don't think I could afford to do it." (Jake, coaching department)

Football has often been framed as a working-class sport although its roots are upper-class: ordered and organised as a professional activity through the public-school systems penchant for codifying and regulating team sports. ${ }^{47}$ However, the professionalisation of football changed the game into a sport for, and played by, the working classes. ${ }^{48}$ There is no direct empirical evidence to support the claim that football has, or is, becoming a more middle-class sport.

The financial implications of employing better quality staff was also highlighted, particularly amongst AMT participants, all of whom had budgetary responsibilities for staffing. The financial burden of employing more qualified and experienced staff was often highlighted as a barrier to quality. Indeed, some staff were referenced by name as not being thought of as sufficient quality to be in their current position, but had managed to go unchallenged as they were the best that could be afforded.

\footnotetext{
“We don't get paid enough... and I know everyone says that, but we don't. If you want good people you've got to be willing to pay for them." (Jim, coaching department)
}

"I think there's a mix of staff. There's those who have bought into science, new ideas...ultimately embracing, or trying to embrace change, then there are those who are more traditional, stuck in their ways...I think a lot of it now comes down to how much we are, willing to compensate and reward." (Scott, AMT) 
The compensation system, ${ }^{57}$ applied to the movement of players between academies, was suggested to be a reason why the club's TI strategy focussed on identifying future potential players as young (early) as possible. Indeed, participants indicated that in order to remain viable or gain an edge on competitors, players would need to be identified and 'in the system' as early as possible. By being in the system, clubs are able to try and retain the services of a player and avoid the potential of having to pay compensation to acquire them from another academy, or purchase players at first team level. Where a player was likely to involve a compensation or purchase fee the process of identifying and recruiting that player became more comprehensive than the club's usual TI process.

"...the big battleground is between 5 and 11 , because the cost of trying to buy somebody is higher after 11, but a lot of the groundwork will have been done by then." (Paul, recruitment department)

“...we can buy from other clubs or pay compensation to other clubs, so it's a bit more in depth in terms of what we're looking for and how many times they get watched." (Josh, AMT)

The notion of identifying talented players at early stages of their lives (i.e. between 5-11 years of age) is in contrast to the existing evidence. This, perhaps, suggests one of two things might be happening: (1) there is a misunderstanding of the literature and its application in practice in football; or (2) there is a disregard, by those with responsibility for implementing such knowledge into practice. The most influential investigations of early specialisation ${ }^{50}$ have demonstrated that the idea of children specialising in a particular sport from an early age is detrimental. This is further supported by studies highlighting the difficulties associated with the early identification of talented athletes, ${ }^{51}$ particularly footballers. ${ }^{52}$ However, whilst there is 
evidence that contradicts the notion of early identification and specialisation, the potential or perceived, financial implications of clubs not adopting such practices appear to proliferate the approach. For example, some clubs find themselves in highly competitive geographic locations (i.e. Greater London) with clusters of clubs at all academy categories competing for the same players. This itself may perpetuate the feeling that clubs need to identify 'early' to ensure they're not missing potential talent.

Data suggest that a balance in the number and quality of scouts identifying players was essential. Whilst there was a clear position that coverage was needed (i.e. numbers) at a local, national, and international scale, it was recognised that sheer volume of scouts and recruitment staff to did ensure reliability (i.e. quality) in the players that would be identified. The quality of scouts was attributed mainly to previous experience and a 'gut feeling' surrounding the ability to identify talented young players. The following statements help to illustrate these points.

“Still, you won't get it right with everyone, so, honestly, I would be upset if I lost my top scouts, as they're better than what anyone else has." (Josh, AMT)

"I suppose it just comes with experience. Through the process there is a back catalogue of players created, and you can compare the players coming through with previous players' performance, in terms of them not being able or being able to do things." (Steve, recruitment department)

"...the only way we judge the scouts is with the players that they present to us and their knowledge and input on other players that they see, when they come in here, or when they deliver reports." (Mike, AMT)

Due to the dearth of work examining the efficacy of scouts within junior-elite football, considerations around what constitutes a high quality or a low-quality scout might be highly variable between, and even within, clubs. Furthermore, the notion of 'experience', which was a term frequently reported, raises more questions about what 
constitutes appropriate experience, and how such experience is attained, measured and assured. Previous coaching studies ${ }^{53}$ have referred to 'gut feeling' or the coaches' 'eye' for identifying talent, with coaches acting as arbiters of taste. ${ }^{54}$ Due to the socially configured nature of football, it is suggested that scouts act in much the same arbitrarily configured manner.

\section{Education}

Education was a discursive subject that included a cross-section of different groups within the academy setting. Education also covered a range of issues, though most prominent was ensuring the best level of education for young players engaged in the full-time training model ${ }^{55}$ (FTTM). Education for players also closely linked with financial implications, with the FTTM investment being highlighted as a significant commitment by the club.

"We are now going into a new era where, previously we only had a couple of age groups that were in full time education, from September we're now going from years 7 to 11 Service, which is a big move." (Josh, AMT)

"Well we can sign a boy from Plymouth now, can't we, we can bring them up here at twelve years of age and house them and, you know, it seems to me, you know, the financial implications are huge." (Scott, AMT)

“you've got to look after them, haven't you? We know the chances of some of them making it are small, but in some of their heads they're already there, think they're already pro. It's important to make sure they've got an education behind them as most are going to need that rather than their football ability." (Jake, coaching department)

The FTTM affords some academies the opportunity to employ more flexible education provision. There is some evidence that flexible approaches to education provision in junior-elite football can have positive outcomes on examination results. ${ }^{56}$ 
However, there is a limited understanding of the educational remit within this environment.

Education and continuing professional development was considered a critical component for full-time and part-time staff. There is explicit guidance in the EPPP ${ }^{57}$ regarding the education requirements for players and continuing professional development (CPD) opportunities for coaches. There is also reference to CPD being a necessary requirement for other staff, such as sport scientists. However, with regard to scouts and recruitment staff, "There are currently no requirements to provide CPD for this category of staff... The education of recruitment staff currently happens 'on the job', via peer relationships and through learned experience. Some innovative Academies have identified this problem and have attempted to improve the situation by staging their own in-service, education programmes."58

"...they [scouts] need to be a better education for them in terms of the FA, there needs to be some more, erm, regulation in terms of like governance in terms of like, you can't just turn up and be a scout...they need more education. We, we offer it now, we give it, but still, you need to have like a tier, level one, level two, level, three." (Jon, recruitment department)

"I think coaching is pretty much sorted, some of the new courses are excellent, the best I've ever done, but I'm not sure what goes on for scouts. Josh probably brings them in every now and then for a chat, but I don't think there is much in-house education going on." (Peter, coaching department)

There were discussions surrounding the use of mentoring strategies, formal and informal education opportunities for scouts and recruitment staff, though the details were vague and typically employed a visit to a neighbouring club to observe 'best practice', though the detail attached to that term was elusive. There are a dearth of studies pertaining to scouts and recruitment staff, however, coach education literature 
supports the idea of a broad and varied educational experiences. ${ }^{59}$ There were reported difficulties in educating part-time members of staff, particularly as many operated in a voluntary capacity.

“The contact which we have with them probably isn't as much as we'd like. We have meetings with them where we try and put these things across and do presentations on different things where we explain our strategies... because of the capacity they're in and because it's a voluntary role". (Kevin, recruitment department)

The role of volunteers, operating in a high-performance environment or on behalf of a high-performance organisation, such as volunteer scouts for professional football clubs, is an unexamined issue. As such, our understanding of the motivations, feeling toward education, amongst other things, is unknown. There is evidence that would suggest the continual development of staff moves beyond up-skilling specific skills or competencies and enhances morale and motivation. ${ }^{60}$

\section{Club Philosophy}

The club's playing philosophy, reportedly, underpinned how potential players were identified and how they should be developed in order to make a successful transition to the first team. However, observational data suggest that despite the clarity and articulation of philosophies and approaches in documentation and interviews, there was a disconnect between philosophy and on-the-ground approach. Indeed, one day during lunch the lead author and two coaches (James \& Karl) were sat talking about the types of players the club seeks to recruit and whether that is reflective of what and how the club positions itself:

Matt questioned: "so, do you not think they're recruiting the players to the club and playing philosophy and looking for potential?" 
Karl and James both laugh, "No chance" James declared, "they're only after kids who can impact a game now, not anyone who might be able to do it in the future". James continued, "they say things that people want to hear, but go away and usually do the opposite. Just look at the size of 'em all...uniform heights."

"I think it's a tough one. Does everyone always align with the philosophy of where they work? I don't know. I don't think we always do, but I'd like to think we always aim to...there are people in different departments who don't talk to each other, though, which makes it difficult to make sure we're all on the same page.

(Scott, AMT)

It has been suggested that it is imperative for professional football clubs and, by extension, their academy, to have a clear philosophy, vision and strategy that is driven by a strong culture. ${ }^{61}$ No two clubs are the same, neither are their cultures or philosophies. It appeared that a clear philosophy and culture was absent in this case. Whilst words were written down and relayed by participants, the disconnect meant that there was ambiguity about how the academy recruitment team and processes were operationalised. The conversation with James \& Karl helps to illustrate this point:

\footnotetext{
"Honestly, Matt, you wouldn't believe some of the shit we get. We have no idea from one week to the next whether there is a lad coming in or not..." said Karl. "Yeah, they [recruitment staff] keep telling us they're looking for the best players in every group, but they're not - well, they are, but they don't know what they're looking for....Most of the lads they're bringing in are just the oldest in their year...they're not particularly great, but they'd run through a wall if you told them to" James added.

"We used to have really small groups compared to most clubs, but that's slowly changing, we're getting bigger groups all the time," Karl stated.
}

Club documentation indicated that there was a desire for the club to recruit only the very best players to the club's academy, thereby suggesting an efficiency model (i.e. low numbers of players and more focussed development opportunities) of operating. However, there was a clear difference between the articulated thoughts on the matter 
and club documentation, with interview data suggesting that the club operates an effectiveness model (i.e. high numbers with a hope some will make it). There is no suggestion that one approach is more beneficial than another, though the model of operating would have implications for the philosophy, values, and approach of the club in its development of junior-elite players.

\section{Competition from other clubs}

There were concerns from participants regarding the level of competition from other clubs in trying to identify and recruit players, particularly within similar geographic locations. All participants discussed the idea of other clubs making illegal approaches or offering enticements for players via family members, or similar. A member of the coaching department, Jake, suggested:

“...the best player has just moved to another club...Get this, they've offered him a 30-grand signing on fee...technically they can't do it, but his dad has said they have, and they're giving him [his dad] two grand a month on top as well." (Jake, coaching department)

Such issues were discussed frequently, though there was never any evidence presented to reaffirm these claims. However, there are clearly issues surrounding competition for clubs to sign players, particularly in areas where there is a particularly high concentration of clubs. There have recently been cases of academies being fined and banned from signing academy players from other clubs because of 'tapping up' ${ }^{62}$ Competition for talented players is so great that there appears to be a perceived need to identify, recruit, and begin developing players at younger and younger ages ${ }^{63}$ despite there being no empirical evidence to support this approach ${ }^{64}$ and practice, as highlighted above, suggesting clubs are, in some cases, still having to pay for players at later stages along the development pathway. Despite the potentially uncertain foundations that early 
identification processes are built upon, it appears to be a deep-rooted issue and accepted aspect of daily life for recruitment staff in football. To date, there is no specific evidence that explores the issues associated with competition from other clubs in the identification and recruitment of young players. There have been regulatory and governance changes brought about through the EPPP, but no evaluation of how effective those changes have been.

\section{Hours in Practice}

Hours in practice was an issue of confusion amongst participants. The notion of deliberate practice has been misappropriated in popular literature ${ }^{65}$ Many participants had become enveloped in the '10,000-hour rule', which appeared to be perpetuated by the coaching hours requirements of the EPPP. ${ }^{66}$ This issue has, perhaps, further driven clubs toward early identification and early specialisation approaches ${ }^{67}$ For example, clubs are not officially allowed to sign players until they are nine years old. However, as a means of getting around this, it is common practice for clubs to operate development centres, or pre-academies for children as young as five years old. This approach appeared to further perpetuate, the notion of achieving an arbitrary number of hours' practice in an attempt to achieve a level of expertise.

“if they were left in a natural environment they wouldn't progress as well as they would here. They still might be great players, but they could have been better if they had been in the environment for longer. I think the younger we can get them the better." (Jim, coaching department)

There has been a considerable amount of research undertaken examining then notion of hours in practice. ${ }^{68}$ One multi-national study ${ }^{69}$ reported that the average age youngsters entered formal academy training was 11.95 years old; though that dropped to 10.06 years old amongst English participants. Furthermore, the focus of the study was 
players at the under-16 age groups, suggesting those still playing academy football at 16 years old did not enter the academy environment until 10 years of age (on average).

This might suggest that identification and recruitment before this time is not ideal and may, potentially, inhibit a players' development due to non-exposure to other sports and activities through specialisation on one sport. Moreover, a study of German professional footballers found that those who achieved national team level specialised later ( 14 years old), and performed more football-related play during childhood. ${ }^{70}$ Practice is clearly a core feature to the development of sport performance, but the age at which specialisation in one sport should occur appears to be less clear.

\section{Current performance and potential talent}

The notion of 'current performance and potential talent' is key to the identification of talent in any field. It highlights the need for those responsible for spotting talent to see beyond performance that stands out at an early age (i.e. current performance) and potential talent that may emerge at a future point (i.e. potential talent). There were several, often interrelated, issues associated with identifying potential talent. Indeed, as noted earlier, there were mixed beliefs about the quality of players being identified and brought into the academy. Some respondents considered that players were being recruited on potential future ability, whilst others suggested identification was based on current ability.

\footnotetext{
“The recruitment staff's skill sets for identifying potential, is limited...anybody who has a clue about football can go out and pick the best player on the pitch on a Sunday, not anybody can go out and spot the one with the most potential...We are picking bigger, stronger, brighter children, the 'now boys', and this is what we seem to get through the door all the time. Very rarely will I see a boy who will be miles away from the required level... when they have been scouted on the pitch it is usually because he is bigger and stronger...our coaches are better at seeing
} 
potential talent, I think they see the nuances in the player, and will look past the physical" (Liam, AMT)

"I think the ones that stand out, would catch your eye straight away. If there were five boxes, they'd tick four of them straight away. It's the other ones that are ticking maybe one or two boxes that I would need to consider more closely... Sometimes it's important to just keep watching, and sometimes you're watching to rule them out." (Paul, recruitment department)

The contention of whether players were selected on current performance or future potential is commonly associated with relative age effect (RAE). Indeed, studies have shown that in youth football, there is an over-representation of players who are born in the first quarter of their selection year. ${ }^{71}$ This often means that the taller, stronger, heavier, and more developed children, than their younger peers, are selected because of their physical characteristics. Those responsible for TI often incorrectly conflate current performance with future potential, where current performance is often the result of more advanced physical capabilities, especially at younger ages. ${ }^{72}$ Data suggest that there was disconnect between departments regarding players identified as talented and the perception of their potential to be successful in the future, opposed their dominance at the present time, representing a plausible RAE divide.

Psycho-social attributes of players were highlighted as important in attempting to understand a players' abilities and future potential. Such traits were often referenced as being the marker of whether a player would make it to senior level or not.

"I would say that the athletic side of it has become really important. Alongside that there is also the mental side, which ultimately filters the best from the rest...that's the difference, you can have all the ability in the world, but you need that desire and passion. The best player I've ever had, didn't make it, because he didn't have that." (Jon, recruitment department) 
“...probably about 12 or 13 years ago, the penny started to drop, as to why these boys were doing better than other boys. It was down to the background, the desire and the passion, to want to be a player, having a good family background, and then a lot of the boys who didn't make it were the best boys, with a poor family background, late turning up for training, lacking desire and passion." (Scott, AMT)

Whilst participants highlighted psycho-social traits and attributes as important when identifying talent, there was an inability to outline exactly what this meant in practice. There is a long-standing interest in psycho-social aspects of performance and development, but little examination of this from an identification perspective. It has been suggested that there are four major psycho-social competencies that contribute to successful development in football: discipline, commitment, resilience, and social support. ${ }^{73}$ The blurred boundary between identification and development is further highlighted here, with key issues for development being purportedly considered during identification, but with no framework for how it should be operationalised. However, it has been suggested that the debate between TI and TD may be 'a purely academic one' ${ }^{74}$

\section{Conclusion}

This study sought to qualitatively explore the factors that affect the identification of junior-elite footballers from the perspective of key stakeholders. A number of important considerations were identified that affect the practice and process of TI in junior-elite football. In the sections above we have highlighted that there appears to be a disconnect between existing research evidence and practice in this particular club.

There was an apparent lack of structure and clarity regarding the TI process within the club, which manifested into a disparity between action 'on the ground' and the reported philosophical approach and values of the academy and club. The relative success that the club had experienced could not be attributed to anything particular in 
the practice that was taking place and may simply be due to luck. We suggest that one of the most important things for the club included to consider and, perhaps, continually re-consider their TI processes and practice. For example, whilst the club had written documentation and participants were able to verbalise the club philosophy, there were contradictory data from participants and observations, suggesting that individuals were doing a myriad of things that may appear to be right at that moment in time, but do not align with the club philosophy or culture. Future studies might consider examining factors affecting TI in junior-elite football with a larger data set and from an international perspective.

One of the most logistically difficult issues for any club to consider in their TI process is how they can educate a workforce that is largely part-time or voluntary. The education of scouts with the most up-to-date scientific and organisational knowledge may be a beneficial step in developing an operational framework for practice that enables better identification of potential talent.

Finally, we suggest that there needs to be a better understanding of 'what' scouts are seeking to identify when looking for players. For example, the importance of psycho-social attributes was highlighted as important, yet all discussion centred around how those factors were examined during in a TD context. Thus, further examination of scouts and talent identifiers' working practices are required to fully understand this phenomenon. 


\section{Notes}

1. For example, Abbott and Collins, 'Eliminating the dichotomy'; Bailey and Morley, 'Towards a model of talent development'; Baker and Schorer, 'Identification and development of talent in sport'.

2. Williams and Reilly, 'Talent identification and development in soccer'; Miller, Cronin and Baker, 'Nurture, nature and some very dubious social skills'.

3. Williams and Reilly, 'Talent identification and development in soccer', 658.

4. Miller, Cronin and Baker, 'Nurture, nature and some very dubious social skills'.

5. Rees et al., 'The great British medalists project'.

6. Balyi and Hamilton, 'Long-term athlete development'; le Gall et al., 'Anthropometric and fitness characteristics'; Meylan et al., 'Talent Identification in Soccer'.

7. Bailey and Collins, 'The problem with the pyramid'; Bailey and Collins, 'The standard model of talent'; Côté, 'The influence of the family in the development of talent in sport'; Côté and Vierimaa, 'The developmental model of sport participation'.

8. MacNamara et al., 'Promoting lifelong physical activity'.

9. Güllich, 'Training Quality in High-Performance Youth Sport'.

10. Faber et al., 'Assessing personal talent determinants'.

11. Côté, 'The influence of the family in the development of talent in sport'.

12. Vaeyens et al., Identifying young players; Abbott and Collins, 'Eliminating the dichotomy'; Durand-Bush and Salmela, 'Becoming a World or Olympic champion'; Vaeyens et al., 'Talent identification and development programmes'.

13. Bailey and Collins, 'The problem with the pyramid'

14. Durand-Bush and Salmela, 'Becoming a World or Olympic champion'; Régnier, Salmela, and Russell, 'Talent detection and development in sport'; Bailey and Collins, 'The problem with the pyramid'

15. Ibid.

16. The Football Association Technical Department, 'Football Education for Young Players'.

17. Premier League, 'Elite player performance plan'.

18. Ibid.

19. Ibid.

20. Vaeyens et al., Identifying young players; Vaeyens, et al., 'Talent identification and development programmes'; Williams and Reilly, 'Talent identification and development in soccer'.

21. Mills et al., 'Identifying factors'; Clarke and Harwood, 'Parenting experiences in elite youth football'; Christensen and Sørensen, 'Sport or school?'

22. le Gall et al., 'Anthropometric and fitness characteristics'; Meylan et al., 'Talent Identification in Soccer'; Figueiredo et al., 'Youth soccer players'.

23. Ibid.

24. Wilson et al., 'Multivariate analyses of individual variation'.

25. Le Moal et al., 'Validation of the Loughborough Soccer Passing Test'.

26. Vaeyens et al., Identifying young players; Meylan et al., 'Talent Identification in Soccer'; le Gall et al., 'Anthropometric and fitness characteristics'; Williams and Reilly, 'Talent identification and development in soccer'. 
27. Williams and Reilly, 'Talent identification and development in soccer'.

28. Mujika et al., 'Fitness determinents'; Hirose, 'Relationships among birthmonth'.

29. Miller, Cronin and Baker, 'Nurture, nature and some very dubious social skills', 645.

30. Christensen and Sørensen, 'Sport or school?'.

31. Christensen, "“An eye for talent"”; Miller, Cronin and Baker, "Nurture, nature and some very dubious social skills'.

32. Clarke and Harwood, 'Parenting experiences in elite youth football'.

33. Morley et al., 'Developmental Contexts and Features'.

34. Crabtree and Miller, 'Research Practice Settings'; Stake, Case studies.

35. Sparkes and Smith, 'Qualitative research methods in sport'.

36. Lincoln and Guba, Establishing trustworthiness, 397-344.

37. Atkinson and Coffey, Analysing documentary realities, 56-75.

38. Watson, Ethnomethodology and textual analysis, 80-98.

39. Patton, "Qualitative research \& evaluation methods".

40. Premier League, 'Elite player performance plan'.

41. Rubin and Rubin, "Qualitative interviewing".

42. Strauss and Corbin, "Basics of qualitative research".

43. Maykut and Morehouse, "Beginning qualitative research".

44. Strauss and Corbin, "Basics of qualitative research".

45. Ibid.

46. The cost for players attending tours was covered by the club, but any parents wishing to accompany/attend were required to pay for themselves.

47. Towson, 'The British at play'.

48. Ibid.

49. Premier League, 'Elite player performance plan', 5.

50. Côté, 'influence of the family'; Côté and Vierimaa, 'development model of sport participation'.

51. Vaeyens et al, 'Talent identification and development'.

52. Unnithan et al, 'Talent identification in youth soccer'.

53. Miller, Cronin and Baker, 'Nurture, nature'; Christensen, 'An eye for talent'.

54. Christensen, 'An eye for talent'.

55. Premier League, 'Elite Player Performance Plan', 13.

56. Christensen and Sørensen, 'Sport or school?'

57. Premier League, 'Elite Player Performance Plan'.

58. Ibid, 75.

59. Cushion, Armour, and Jones, 'Coach education'.

60. Armour, 'Effective career-long professional development'.

61. Nesti \& Sulley, 'Youth development in football'.

62. Hunter, 'Liverpool banned'; Press Association, 'Manchester City Banned'.

63. Unnithan et al, 'Talent identification in youth soccer'.

64. Bailey and Collins, 'The problem with the pyramid'.

65. Gladwell, 'Outliers'.

66. Premier League, 'Elite player performance plan', 31.

67. Côté, 'influence of the family'. 
68. Ford et al, 'The development activities'; Haugaasen, Toering and Jordet, 'From childhood to senior'; Horning, Aust and Güllich, 'Practice and play'.

69. Ford et al, 'The development activities'.

70. Horning, Aust and Güllich, 'Practice and play'.

71. Vaeyens, Philippaerts and Malina, 'The relative age effect in soccer'; Helsen, Winckel and Williams, 'The relative age effect in youth soccer across Europe'.

72. Bailey and Collins, 'The problem with the pyramid'.

73. Holt and Dunn, 'Toward a grounded theory'.

74. Miller, Cronin and Baker, 'Nurture, nature and some very dubious social skills', 653. 


\section{References}

Abbott, Angela, and Dave Collins. "Eliminating the Dichotomy between Theory and Practice in Talent Identification and Development: Considering the Role of Psychology." Journal of Sports Sciences 22, no. 5 (2004): 395-408. doi:10.1080/02640410410001675324.

Armour, Kathleen M. "Effective Career-Long Professional Development for Teachers and Coaches.” In Sport Pedagogy: An Introduction for Teaching and Coaching, edited by Kathleen M. Armour, 227-29. London: Routledge, 2013.

Atkinson, Paul, and Amanda Coffey. "Analysing Documentary Realities.” In Qualitative Research, edited by David Silverman, 56-75. London: Sage, 2011.

Bailey, Richard P., and Dave Collins. "The Standard Model of Talent Development and Its Discontents.” Kinesiology Review 2, no. 4 (2013): 248-59.

Bailey, Richard, and Dave Collins. "The Problem with the Pyramid: Why Most Models of Talent Development Are Flawed." In Elite Sport and Sport-for-All: Bridging the Two Cultures? edited by Richard Bailey and Margaret Talbot, 72-84. London: Routledge, 2015.

Bailey, Richard, and David Morley. "Towards a Model of Talent Development in Physical Education.” Sport, Education and Society 11, no. 3 (2006): 211-30. doi:10.1080/13573320600813366.

Baker, Joe, and Jorg Schorer. "Identification and Development of Talent in Sport." Talent Development and Excellence 2, no. 2 (2010): 119-21.

Balyi, Istvan, and Ann Hamilton. "Long-Term Athlete Development Update: Trainability in Childhood and Adolescence." Faster, Higher, Stronger 20 (2003): 6-8.

Christensen, Mette Krogh. “'An Eye for Talent': Talent Identification and the 'practical Sense' of Top-Level Soccer Coaches.” Sociology of Sport 26, no. 3 (2009): 36582.

Christensen, Mette Krogh, and Jan Kahr Sørensen. "Sport or School? Dreams and Dilemmas for Talented Young Danish Football Players." European Physical Education Review 15, no. 1 (2009): 115-33. doi:10.1177/1356336X09105214.

Clarke, Nicola J., and Chris G. Harwood. "Parenting Experiences in Elite Youth Football: A Phenomenological Study.” Psychology of Sport and Exercise 15, no. 5 (2014): 528-37. doi:10.1016/j.psychsport.2014.05.004. 
Côté, Jean. "The Influence of the Family in the Development of Talent in Sport." The Sport Psychologist 13, no. 1995 (1999): 395-417. doi:10.1177/1527002502003003001.

Côté, Jean, and Matthew Vierimaa. “The Developmental Model of Sport Participation: 15 Years after Its First Conceptualization.” Science \& Sports 29 (2014): S63-69. doi:10.1016/j.scispo.2014.08.133.

Crabtree, Benjamin F, and William L Miller. "Research Practice Settings: A Case Study Approach.” In Doing Qualitative Research, edited by Benjamin F Crabtree and William L Miller, 293-312. London: Sage, 1999.

Cushion, Christopher J., Kathy M. Armour, and Robyn L. Jones. "Coach Education and Continuing Professional Development: Experience and Learning to Coach.” Quest 55, no. 3 (2003): 215-30. doi:10.1080/00336297.2003.10491800.

Durand-Bush, Natalie, and John. H. Salmela. "Becoming a World or Olympic Champion: A Process rather than an End Result." In Proceedings of the Xth World Congress of Sport Psychology, edited by A. Papaioannou, M. Goudas, and Y. Theodorakis, 300-302. Skiathos, Greece: Christodoulidi Publications, 2001.

Faber, Irene R, Paul M.J. Bustin, Frits G.J. Oosterveld, Marije T Elferink-Gemser, and Maria W.G. Nijhuis-Van der Sanden. “Assessing Personal Talent Determinants in Young Racquet Sport Players: A Systematic Review.” Journal of Sports Sciences 34, no. 5 (2016): 395-410. doi:10.1080/02640414.2015.1061201.

Figueiredo, António J., Carlos E. Gonçalves, Manuel J Coelho E Silva, and Robert M Malina. "Youth Soccer Players, 11-14 Years: Maturity, Size, Function, Skill and Goal Orientation.” Annals of Human Biology 36, no. 1 (2009): 60-73. doi:10.1080/03014460802570584.

Ford, Paul R., Christopher Carling, Marco Garces, Mauricio Marques, Carlos Miguel, Andrew Farrant, Andreas Stenling, et al. "The Developmental Activities of Elite Soccer Players Aged under-16 Years from Brazil, England, France, Ghana, Mexico, Portugal and Sweden.” Journal of Sports Sciences 30, no. 15 (2012): 1653-63. doi:10.1080/02640414.2012.701762.

Gladwell, Malcolm. Outliers: The Story of Success. New York, NY: Little, Brown \& Company, 2008. 
Güllich, Arne. “Training Quality in High-Performance Youth Sport.” In Science for Success Conference, 11-12 October. Research Institute for Olympic Sports (KIHU), Finland, 2011.

Haugaasen, Mathias, Tynke Toering, and Geir Jordet. "From Childhood to Senior Professional Football: A Multi-Level Approach to Elite Youth Football Players' Engagement in Football-Specific Activities." Psychology of Sport and Exercise 15, no. 4 (2014): 336-44. doi:10.1016/j.psychsport.2014.02.007.

Helsen, Werner F., Jan Van Winckel, and A. Mark Williams. "The Relative Age Effect in Youth Soccer across Europe." Journal of Sports Sciences 23, no. 6 (2005): 629-36. doi:10.1080/02640410400021310.

Hirose, Norikazu. "Relationships among Birth-Month Distribution, Skeletal Age and Anthropometric Characteristics in Adolescent Elite Soccer Players.” Journal of Sports Sciences 27, no. 11 (2009): 1159-66. doi:10.1080/02640410903225145.

Holt, Nicholas L., and John G. H. Dunn. "Toward a Grounded Theory of the Psychosocial Competencies and Environmental Conditions Associated with Soccer Success." Journal of Applied Sport Psychology 16, no. 3 (2004): 199219. doi:10.1080/10413200490437949.

Hornig, Manuel, Friedhelm Aust, and Arne Güllich. "Practice and Play in the Development of German Top-Level Professional Football Players.” European Journal of Sport Science 16, no. 1 (2016): 96-105. doi:10.1080/17461391.2014.982204.

Hunter, Andy. "Liverpool Banned from Signing Academy Players and Fined $£ 100,000$.” The Guardian. 5 April 2017. https://www.theguardian.com/football/2017/apr/05/liverpool-banned-signingacademy-players-fined-stoke.

le Gall, Franck, Chris Carling, A. Mark Williams, and Tom Reilly. “Anthropometric and Fitness Characteristics of International, Professional and Amateur Male Graduate Soccer Players from an Elite Youth Academy.” Journal of Science and Medicine in Sport 13, no. 1 (2010): 90-95.

Le Moal, Emmeran, Olivier Rue, Ali Ajmol, Abderaouf B. Abderrahman, Mohammed A. Hammami, Omar B. Ounis, Wiem Kebsi, and Hassane Zouhal. "Validation of the Loughborough Soccer Passing Test in Young Soccer Players.” Journal of Strength and Conditioning Research 28, no. 5 (2014): 1418-26. doi:10.1519/jsc.0000000000000296. 
Lincoln, Yvonna, and Egon Guba. "Establishing Trustworthiness." In Qualitative Research (Volume III), edited by Alan Bryman and Robert. G. Burgess, 397434. London: Sage, 1999.

MacNamara, Áine, Dave Collins, Richard Bailey, Martin Toms, Paul Ford, and Gemma Pearce. "Promoting Lifelong Physical Activity and High Level Performance: Realising an Achievable Aim for Physical Education." Physical Education \& Sport Pedagogy 16, no. 3 (2011): 265-78. doi:10.1080/17408989.2010.535200.

Maykut, Pamela, and Richard Morehouse. Beginning Qualitative Research: A

Philosophical and Practical Guide. Lewes, UK: Falmer Press, 1994.

Meylan, Cesar, John Cronin, Jon Oliver, and Michael Hughes. "Talent Identification in Soccer: The Role of Maturity Status on Physical, Physiological and Technical Characteristics." International Journal of Sports Science and Coaching 5, no. 4 (2010): 571-92.

Miller, Paul K., Colum Cronin, and Graham Baker. "Nurture, Nature and Some Very Dubious Social Skills: An Interpretative Phenomenological Analysis of Talent Identification Practices in Elite English Youth Soccer." Qualitative Research in Sport, Exercise, and Health 7, no. 5 (2015): 642-62.

doi:10.1080/2159676X.2015.1012544.

Mills, Andrew, Joanne Butt, Ian Maynard, and Chris Harwood. "Identifying Factors Perceived to Influence the Development of Elite Youth Football Academy Players.” Journal of Sports Sciences 30, no. 15 (2012): 1593-1604. doi:10.1080/02640414.2012.710753.

Morley, David, Gareth Morgan, Jim McKenna, and Adam R. Nicholls. "Developmental Contexts and Features of Elite Academy Football Players: Coach and Player Perspectives.” International Journal of Sports Science \& Coaching 9, no. 1 (2014): 217-32. doi:10.1260/1747-9541.9.1.217.

Mujika, Iñigo, Juanma Santisteban, Franco M. Impellizzeri, and Carlo Castagna. "Fitness Determinants of Success in Men's and Women's Football." Journal of Sports Sciences 27, no. 2 (2009): 107-14. doi:10.1080/02640410802428071.

Nesti, Mark, and Chris Sulley. Youth Development in Football: Lessons from the World's Best Academies. Oxon: Routledge, 2014.

Patton, Michael Q. Qualitative Research \& Evaluation Methods. 3rd ed. London: Sage, 2002.

Premier League. "Elite Player Performance Plan.” London, 2011. 
Press Association. "Manchester City Banned from Signing Certain Academy Players over Tapping up.” The Guardian. May 5, 2017.

Rees, Tim, Lew Hardy, Arne Güllich, Bruce Abernethy, Jean Côté, Tim Woodman, Hugh Montgomery, Stewart Laing, and Chelsea Warr. "The Great British Medalists Project: A Review of Current Knowledge on the Development of the World's Best Sporting Talent.” Sports Medicine 46, no. 8 (2016): 1041-58. doi:10.1007/s40279-016-0476-2.

Régnier, G, J Salmela, and S Russell. “Talent Detection and Development in Sport.” In Handbook on Research on Sport Psychology, edited by Robert N. Singer, Milledge Murphey, and L. Keith Tennant, 290-313. New York: Macmillan, 1993.

Rubin, Herbert J, and Irene S Rubin. Qualitative Interviewing: The Art of Hearing Data. London: Sage, 1995.

Sparkes, Andrew C., and Brett Smith. Qualitative Research Methods in Sport, Exercise and Health: From Process to Product. Oxon: Routledge, 2014.

Stake, Robert E. “Case Studies.” In Handbook of Qualitative Research, edited by Norman K. Denzin and Yvonna S. Lincoln, 2nd ed., 435-54. London: Sage, 2000.

Strauss, Anselm, and Juliet M. Corbin. Basics of Qualitative Research: Techniques and Procedures for Developing Grounded Theory. 2nd ed. London: Sage, 1998.

The Football Association Technical Department. "Football Education for Young Players: “A Charter for Quality.”' London, 1997.

Townson, Nigel. The British at Play - a Social History of British Sport from 1600 to the Present. Bucharest, Romania: Cavallioti Publishers, 1997.

Unnithan, Viswanath, Jordan White, Andreas Georgiou, John Iga, and Barry Drust. “Talent Identification in Youth Soccer.” Journal of Sports Sciences 30, no. 15 (2012): 1719-26. doi:10.1080/02640414.2012.731515.

Vaeyens, Roel, Manuel J Coelho e Silva, Chris Visscher, Renaat M Philippaerts, and A. Mark Williams. "Identifying Young Players." In Science and Soccer: Developing Elite Performers, edited by A. Mark Williams, 3rd ed., 289-306. London: Routledge, 2013.

Vaeyens, Roel, Matthieu Lenoir, A. Mark Williams, and Renaat M. Philippaerts. "Talent Identification and Development Programmes in Sport: Current Models and Future Directions.” Sports Medicine 38, no. 9 (2008): 703-14. 
Vaeyens, Roel, Renaat M. Philippaerts, and Robert M. Malina. “The Relative Age Effect in Soccer: A Match-Related Perspective.” Journal of Sports Sciences 23, no. 7 (2005): 747-56. doi:10.1080/02640410400022052.

Watson, Rod. "Ethnomethodology and Textual Analysis." In Qualitative Research, edited by David Silverman, 80-98. London: Sage, 1997.

Williams, A. Mark, and Tom Reilly. "Talent Identification and Development in Soccer.” Journal of Sports Sciences 18, no. 9 (2000): 657-67. doi:10.1080/02640410050120041.

Wilson, Robbie S., Rob S. James, Gwendolyn David, Ecki Hermann, Oliver J. Morgan, Amanda C. Niehaus, Andrew Hunter, Doug Thake, and Michelle D. Smith. "Multivariate Analyses of Individual Variation in Soccer Skill as a Tool for Talent Identification and Development: Utilising Evolutionary Theory in Sports Science.” Journal of Sports Sciences 34, no. 21 (2016): 2074-86. doi:10.1080/02640414.2016.1151544. 